\title{
Shakespeare across the Taiwan Strait: A Developmental Perspective ${ }^{1}$
}

\begin{abstract}
Shakespeare studies in Mainland China and Taiwan evolved from the same origin during the two centuries after Shakespeare being introduced into China in the early nineteenth century. Although Shakespeare was first seen on the Taiwan stage in the Japanese language during the colonial period, it was after Kuomintang moved to Taiwan in 1949 that Shakespeare studies began to flourish when scholars and theatrical experts from mainland China, such as Liang Shih-Chiu, Yu Er-Chang, Wang Sheng-shan and others brought Chinese Shakespeare to Taiwan. Since the 1980s, mainland Shakespeareans began to communicate actively with their colleagues in Taiwan. With the continuous efforts of Cao Yu, Fang Ping, Meng Xianqiang, Gu Zhengkun, Yang Lingui and many other scholars in mainland China and Chu Li-Min, Yen Yuan-shu, Perng Ching-Hsi and other scholars in Taiwan, communications and conversations on Shakespeare studies across the Taiwan Strait were gradually enhanced in recent years. Meanwhile, innovations in Chinese adaptations of Shakespeare have resulted in a new performing medium, Shake-xiqu, through which theatrical practitioners on both sides explore possibilities of a union of Shakespeare and traditional Chinese theatre. This paper studies some intricate relationship in the history of Shakespeare studies in mainland China and Taiwan from a developmental perspective and suggests opportunities for positive and effective co-operations and interactions in the future.
\end{abstract}

Keywords: Shakespeare Studies, China, Mainland, Taiwan, Shake-xiqu.

\footnotetext{
* Assistant researcher in the College of Foreign Languages and Cultures, Xiamen University, Xiamen, Fujian Province, China.

** Professor in Min Nan Normal University, Zhangzhou and the College of Foreign Languages and Cultures, Xiamen University, Xiamen, Fujian Province, China.

${ }^{1}$ This paper is sponsored by China National Key Research Project in Arts Studies "Frontiers of Contemporary Theatre Theories in the West" (No.18ZD06). We would like to show our deepest gratitude to Prof. Yang Lingui, who has walked us through all the stages of the writing of this paper. Without his illuminating instruction and patience, this paper could not have reached its present form.
} 
In recent years, the cross-cultural adaptations of Shakespeare's plays in Asia have gradually become a focus of international Shakespeare studies. The achievements of Shakespeare studies in Chinese context have greatly enriched international Shakespeare studies. Chinese translations of Shakespeare's plays have facilitated Shakespeare performances and studies on both sides of the Taiwan Strait. Taiwan Shakespeare studies, as an important part in the field of foreign literature and theatre studies, shares the same origin with the ones in mainland China. However, the different tracks of development in Shakespeare studies in mainland China and Taiwan reflect different social and political conditions. In the process of cultural appropriation of Shakespeare's plays, mutual understanding and communications on both sides can help to elevate Chinese traditional operas to a new stage and realize the maximum dissemination of Chinese culture in the age of globalization.

The development of Shakespeare studies on both sides of the Taiwan Strait witnesses the social changes and historical evolution and shows the alternation and intersection of the powers of discourse. In Taiwan, particularly, the relations between drama and politics are always intertwined. The reception history of Shakespeare's plays in Taiwan can be divided into four phases: Japanese Colonial Period, Kuomintang Martial Law Period, the period between the end of Martial Law and the end of twentieth century, and the period of the beginning of the twenty-first century to the present. Meanwhile, adaptations of Shakespeare's plays into various xiqu (traditional Chinese opera) forms, namely Shake-Xiqu, have strengthened ties in cultural traditions between the two sides.

\section{Common Origins of Mainland China and Taiwan Shakespeare Studies}

Shakespeare's name was already heard in Chinese in various versions in the 1800 s, and his Chinese name was standardized in the early twentieth century. In 1839, the English Bard's name first appeared as 沙士比阿(Sha-shi-bi-a) in a Chinese book, Sizhou zhi, translation of Hugh Murray's The Encyclopaedia of Geography, a project organized by Lin Zexu (1785-1850). In 1856, William Muirhead, a British Protestant missionary, also mentioned the name of Shakespeare in his Chinese translation of Thomas Milner's The History of England. Among almost a dozen of his Chinese names, one remains as the standard accepted on both sides of the Taiwan Straits till now, and that is 莎士比 亚(Sha-shi-bi-ya). This is a coinage by Liang Qichao in his Critique on Poetry in Icy Drinks Room published in 1902, when he acclaimed that "among poets of recent times, Shakespeare (Shashibiya), Milton and Tennyson were very great, as their poems amounted to thousands of words" (qtd. in Meng 5). 
The early twentieth century saw Shakespeare's works in Chinese characters. However, the first Chinese publications under Shakespeare's name were not translations of his works but their adaptations. In 1903, Da Wen Press in Shanghai published a booklet entitled Xie Wai Qi Tan (Exotic Tales), in which 10 Shakespearean stories were translated by an anonymous translator. In the following year, Lin Shu and Wei Yi collaborated Yin Bian Yan Yu (Chitchat of an English Poet), which was published by Shanghai Commercial Press, including the translation of 20 stories from Tales from Shakespeare written by Charles Lamb and Mary Lamb. Lin Shu's translation made Shakespeare's plays popular among common Chinese readers and exerted a great influence on both sides of Taiwan Strait. In June and July 1906, in the Chinese version of Taiwan Daily News, three short stories written in ancient style by an author with the penname of Shao Chao were considered as the rewritings of Lin Shu's translation of stories of Shakespeare's plays (Xu "Research" 251). The three short stories were entitled Danish Prince, Edge Glass and Jade Toad, which were respectively adapted from Hamlet, All's Well That Ends Well and A Collection of Bizarre Stories by Pu Songling of Qing Dynasty, and As You Like It, according to $\mathrm{Xu}$ Junya, a scholar in Taiwan Normal University, who made a detailed research on the spread of Chitchat of an English Poet in Taiwan. Her research showed that during the period of Japanese colonization, the Chinese literary circle in Taiwan was influenced by Lin Shu's translation of Tales from Shakespeare, thus gaining an initial understanding of Shakespeare's plays (Xu "Early Propagation" 42). In addition to the translation of the tales, Lin Shu also collaborated with Chen Jialin and translated four historical plays, Richard $I I$, Henry IV, Henry $V$, Henry $V$ and Julius Caesar from Historical Tales from Shakespeare written by A. T. Quiller-Couch, according to Tarumoto Teruo in The Book on the Unjust Case of Lin Shu (2008). ${ }^{2}$

In 1931, Liang Shih-chiu (1903-1987), a professor in National Qingdao University, began to translate Shakespeare's plays with the advocacy and encouragement of Hu Shih (1891-1962), a great scholar, thinker, poet, historian and writer of modern China. Liang Shih-chiu finished the translation of ten Shakespeare's plays in the mainland and had seven of them published by the Commercial Press before he left for Taiwan in 1949 and taught in Taiwan Normal University. In 1967, he completed the translation of thirty-seven Shakespeare's plays with painstaking efforts. Until now he is still the only one that has completed the Chinese translation of Shakespeare's plays solely on one's own. Liang Shih-chiu had a great influence on Taiwan Shakespeare studies during the period of the martial law (1949-1987).

2 The book tries to justify Lin Shu and his translation by examining the various sources and changes of evaluations on Lin Shu's translation. It was translated into Chinese in 2018 and published by Commercial Press in Shanghai. 
Along with Liang's The Complete Works of Shakespeare, Zhu Shenghao's translation, as edited by Yu Erchang, has been well received in Taiwan since its publication in 1957. Zhu Shenghao (1912-1944), a poet and graduate from Hangchow Christian College (now Zhejiang University), was a crucial figure in the history of Chinese translation of Shakespeare's plays. He began to translate Shakespeare's plays in 1935. During the Sino-Japanese War, he translated 31 and half Shakespeare's plays (previously considered as 27 and half) until his death. His translation was first published by World Publishing House in Shanghai in 1947. His translation of Shakespeare's plays is highly acclaimed by the readers from both sides of the Taiwan Strait for its poetic rhythm and vivid expressions and is extensively used in various theatres.

To a certain extent, both Liang Shih-chiu's and Zhu Shenghao's translations have completed the process of Shakespeare's Chinese canonization through historical tests. Although Zhu Shenghao's translation is considered to be classic, he translated the poetic lines in prose, with too many omissions, modifications and obfuscations, which affect the plays' integrity. For instance, one of the concerns raised by translation critics is Zhu Shenghao's deleting of Shakespeare's bawdy expressions. "The act of purifying involves the translator's hard work, but it is not worth advocating if we correctly judge how to treat foreign classics" (Zhu Jungong 24). Liang Shih-chiu translated Shakespeare's original plays in prose style yet with the rhythm of a prose poem. Liang's translation makes up for the missing portions and intentional mistranslation of the sexually implied texts in Zhu's version, and restores the vivid Shakespearean world of the English Renaissance. As for the translation of sexual hints and vulgar language, that is confined within the social environment of the time and the translator's style. Although sexual hints are not deleted in Liang's translation, his prose is sometimes criticized to be too straightforward and lacks the poetic rhythm of the original lines.

Yu Er-chang (1904-1984), a schoolmate of Zhu Shenghao, came to Taiwan in 1949 and began to teach in the department of Foreign Languages in National Taiwan University and translated the remaining 10 Shakespearean historical plays that he thought Zhu had not finished. In 1957, the translation of The Complete Works of William Shakespeare collaborated by Zhu Shenghao and $\mathrm{Yu}$ Er-chang was published by World Publishing House in Taiwan. However, the two long poems Venus and Adonis and The Rape of Lucrece were excluded from The Complete Works of William Shakespeare.

The two versions of Complete Shakespeare translated by Liang Shihchiu, Zhu Sheng-hao and Yu Er-chang have always been the main accesses for readers in Taiwan to appreciate Shakespeare's plays. The same origin of mainland China and Taiwan Shakespeare studies cannot be denied. In Chinese Shakespeares: Two Centuries of Cultural Exchange, Alex Huang approvingly recognizes the shared origin of Shakespeare studies in mainland China and 
Taiwan by focusing on the sinicization of Shakespeare after his entering the Chinese world, discussing the different situations of Shakespeare's plays in various historical stages in mainland China and Taiwan, including the period of the Anti-Japanese War, the cultural revolution period in mainland China and the martial law period in Taiwan.

\section{Shakespeare's Plays in Taiwan during Japanese Colonial Period and Early Post-War Period}

The records of a few Japanese adaptations of Shakespeare's plays in Taiwan during the period of Japanese colonization (1895-1945) show that they were equipment of the colonial rule. According to $\mathrm{Wu}$ Peichen, the Japanese Shakespeare's plays staged in Taiwan during the colonial years were for the entertainment of the conquerors or the Japanese speaking audiences ("The Peripheral Body of Empire" 235). There is no evidence about the reception of Japanese Shakespeare's plays by the native people in Taiwan, as during that period the audience was mainly Japanese who lived in Taiwan. The performances were based on Japanese translations by such translator as Shoyo Tsubouchi (1859-1935). As Chen Yilin notes, "Shakespeare's plays staged in Taiwan were sporadically performed by Japanese troupes" in the early stage of the colonial time (1895-1915) and later on the Japanese government "promoted English language and culture so that some of the common people could read Shakespeare's plays in Japanese and some elites could read the original Shakespeare's plays in English" (Chen Yilin 1). In "Japanese campaigns" (Chiu A Study on Taiwan Theatre 10) at the end of Japanese Colonial Period (19371945), traditional Chinese operas were banned, and performances in theatre were controlled. They were replaced by the imperial drama of Japanese militarism. During this period, British and American literature and culture were expelled out of the educational system. The campaigns nearly changed the inherent Chinese cultural traditions and national identity of the people in Taiwan.

There is, ironically, some Taiwanese element in the Japanese adaptations as a vehicle of discrimination against the colonized. In 1903, Kawakami Otojiro, who launched "Drama Movement" in Japan, staged Osero $\left(\right.$ Othello) ${ }^{4}$ in Tokyo, with its setting in Japan and Taiwan in Meiji era. Cyprus in the original play was changed into Penghu Islands. Othello, the Moor, was

3 It referred to "a new type of drama that is not traditional kabuki or borrows parts of its content and form" (Shi 78).

${ }^{4}$ Related research on the play may refer to Yukari Yoshihara, "Raw-Savage's Othello: The First-staged Japanese Adaptation of Othello (1903) and Japanese Colonialism," Shakespeare and the Ethics of Appropriation, 2014. 
adapted into Muro Washiro, a tribal-born governor working for the Japanese emperor's colonial rule over Taiwan. Iago's Japanese name was Iya. Desdemona was adapted into the daughter of Chancellor of the Exchequer, Tomone. This role was performed by the wife of Kawakami, Sadayakko, the first modern actress in Japan (Hiroshi 277). In the play, after Muro Washiro killed his wife, he realized his blunder and said: "I abandoned my precious one. It's too late to regret. I'm a fool as an aborigine. I'm doomed to death" (qtd. in Wu "Japanese Adaptation of Othello" 41). This adaptation of Othello reflects the feudal ideas of race and class categorization in Japanese society at that time, as well as the racial discrimination against the indigenous people in Taiwan, when they were forced to accept the Japanese colonial rules.

According to the Japanese version of Taiwan Daily Newspaper published from 1895 to 1945, Osero was staged in Taiwan in 1905, in which "Masao Murata and Mohee Fukui performed as the protagonists" (Wu "Japanese Adaptation of Othello" 44). Wu Peichen also compared Othello 1905 with The Tempest 2004 staged by Wu Shing-kuo in the Contemporary Legend Theatre to show the social and political changes in Taiwan (Wu, The Peripheral Body of Empire 235). However, the relevant information about the reception of these Japanese Shakespeare's plays by the native people in Taiwan has not been found until now. It can be seen that Shakespeare's plays staged by Japanese troupes in Taiwan have not had any impact on the native people in Taiwan.

Upon the Japanese surrender in 1945 and till 1949, the Kuomintang government promoted the literature and art movement with fighting spirit. In terms of literary and art policies, the government aiming at "de-japanization" and "re-sinicization" (Huang Yingzhe "De-japanization" 17) in Taiwan, actively promoted the cultural construction by establishing a new cultural system that was centred on Chinese traditional culture, and re-integrated Taiwan into the Chinese cultural circle. It was in this period that Chen Dayu, a director from Zhangzhou, Fujian province went to Taiwan in 1946 to participate in the cultural construction in post-war Taiwan. After his arrival, Chen Dayu led the "Little Experimental Troupe" and launched his theatrical career in Taiwan in just two years and six months (1946.10-1949.4). The troupe had performed Molière's Miser, Poor Figa (co-performed with the Youth Art Drama Society) and Cao Yu's The Field in Yat-sen Hall of Taipei. ${ }^{5}$ However, the February $28^{\text {th }}$ Incident in 1947 made the atmosphere of white terror continue to envelop Taiwan society, which also seriously affected the development of post-war Taiwan theatre.

${ }^{5}$ Yat-sen Hall, located in the western district of Taipei city, was built in 1932. It was one of the important construction projects of the colonial government to celebrate Japanese emperor Hirohito's accession to the throne. In 1945, Yat-sen Hall was the place where the Chinese government held a ceremony to celebrate Japan's defeat and surrender in Taiwan. 
According to many written records, the first Chinese Shakespeare's play staged in Taiwan was Clouds of Doubt adapted from Othello directed by Chen Dayu. ${ }^{6} \mathrm{He}$ had established the Little Experimental Troupe in Zhangzhou. After arriving in Taipei, the theatre recruited many native players. Chen Dayu divided the cast into two groups: a group of mandarin speakers, mainly from other provinces of China and a group of Hokkien speakers, consisting of people from Fujian Province and native people in Taiwan. His play Banana Fragrance ${ }^{7}$ was banned by the Kuomintang authorities in 1947, as it reflected the conflicts between the native people in Taiwan and the people who came to Taiwan with the retreat of Kuomintang, thus causing riots in auditorium. According to the newspaper Taiwan New Life and its supplement The Bridge, which were published during the years of 1947-1949, Clouds of Doubt was to be staged in Taipei. However, after a thorough research done by the author and Chiu Kunliang, an expert in the history of Taiwan theatre, no strong evidence that the play Clouds of Doubt was staged in 1949 was found until now.

On Taiwan New Life $e^{8}$ on $31^{\text {st }}$ January 1949, a literary review on Othello written by Shoyo Tsubouchi was translated into Chinese, which served as an

$6 \mathrm{Lv}$ Su-shang, the first scholar who did research on post-war theatrical studies in Taiwan, recorded in his famous work History of Film and Theatre in Taiwan: "At the end of February 1949, a small experimental troupe will rehearse Clouds of Doubt, the adaptation of Shakespeare's Othello (adapted and directed by Chen Dayu). The play will be staged at the auditorium of Taipei No. 1 middle school. Without public ticket sales, tickets will be distributed to the audience" (Lv 366). Jiao Tong, a writer and theatrical scholar, recorded in his work The Early Postwar Theatre in Taiwan: "At the end of February 1949, the 'Little Experimental Troupe' performed Clouds of Doubt in the auditorium of Taipei No. 1 middle school. It was adapted from Shakespeare's Othello by Chen Dayu" (Jiao 179).

${ }^{7}$ Prior to Clouds of Doubt, Banana Fragrance is a well-known play directed by Chen Dayu, which occupies an important position in Taiwan theatre. The play alludes to the most sensitive political and ethnic issues in the "Feb. $28^{\text {th }}$ Incident," showing the serious conflicts between "natives" and "outsiders." On November 1 1 , 1947 , Banana Fragrance was performed in Yat-sen Hall of Taipei at night, but caused a quarrel between the local audience and the audience from the other provinces, causing a sensation. It was scheduled to be performed for six times in three days. As the plot involved ethnic conflicts, after the first performance, the play was banned by the Taiwan news agency.

${ }^{8}$ Launched on August $1^{\text {st }}, 1947$, the newspaper supplement of Taiwan New Life, The Bridge, altogether published 223 issues until April $11^{\text {th }} 1949$, on which Chen Dayu published his main viewpoints on Taiwan drama and literature. On April $2^{\text {nd }}, 1948$, The Bridge published an article entitled "How to Build a Contemporary Drama Movement" written by Chen Dayu. In the article, Chen made a comprehensive analysis on the current situation of Taiwan's drama performance and gave specific suggestions on how to develop drama movement. 
introduction to the upcoming play Clouds of Doubt and was released by the Advocacy Group of the Little Experimental Troupe. This is the only objective evidence that can be found during the early post-war period. In Alexa Huang's account of Shakespeare in China, Clouds of Doubt is also considered "the earliest documented Chinese-language Shakespeare performance in Taiwan" (10).

Beatrice Bi-qi Lei adds more details about the performance in an interview in Chinese:

The play Clouds of Doubt adapted from Othello showed that the male and female protagonists with different colors of skin fell in love and got married, but led to a tragic ending. With the adaptation of Shakespeare's play, Chen Dayu, as an artist, expressed his pessimistic attitude towards Taiwan society and his desire for ethnic harmony through the platform of theatre in the early postwar period. (Chiu and Lei)

In the introduction to Re-playing Shakespeare in Asia, Poonam Trivedi reiterates that "the first production of Shakespeare in Taiwan was Yi Yun (Suspicion), an adaptation of Othello in 1949" (Trivedi 16). That "Clouds of Doubt was staged in Taiwan in 1949" seems to have become a convincing fact. Suspicion on it will only make the readers feel that there is no point in stirring up the trouble. However, in the paper "I May Be Straight, Though They Themselves Be Bevel': Taiwan's Early Shakespeare" written by Beatrice Bi-qi Lei, she mentioned the play The Story of Revenged Prince adapted from Hamlet in 1962 and took the same play staged in 1964 as "the first public performance of Shakespearean masterpiece in Free China" (Lei 94). The contradictory statements on the first Chinese Shakespeare play staged in Taiwan are very confusing.

In 2006, the book Drifting for Thousands of Miles: Chen Dayu was published by the Cultural Construction Committee of the Executive Council of Taiwan. Written by Chiu Kun-liang, it was the only monograph on the life and theatrical works of the dramatist Chen Dayu. In order to write the book, Chiu Kun-liang went to Chen Dayu's hometown Zhangzhou and visited his family. After checking out Min Nan Newspaper on May 15th 1941, he found that Clouds of Doubt adapted from Othello had once been staged by Chen Dayu in Zhangzhou for the first time in May 1941. In the fifth chapter of the book, Chiu Kun-liang wrote:

The works directed by Chen Dayu in his Taiwan period were produced from 1948 to the beginning of 1949. The performance plan of Chen Dayu's Little Experimental Troupe did not go smoothly, and the public performances of Taipei Restaurant and Clouds of Doubt (Shakespeare's Othello) were not staged as scheduled (Chiu, Drifting 142). 
As Jiao Tong, a theatre scholar of post-war Taiwan drama, puts:

Due to the long-term geographical and historical separation between Taiwan and the mainland, the political, economic, social upheaval caused the ethnic conflicts and misunderstandings. The friction caused by misunderstanding and conflicts directly caused the political environment to be more serious. Taiwan paid very high social and cultural costs in the early years of restoration. (Jiao 10)

In the historical torrent, Chen Dayu came to Taiwan from the mainland out of his personal choice and ambition. In a dangerous political situation, Chen Dayu went back to the mainland secretly in April 1949, but his persistence and enthusiasm for drama had given new hope to the distressing Taiwan theatre. Even if Clouds of Doubt was not performed as scheduled, it sowed seeds for the vigorous development of Shakespeare's plays in Taiwan. Inspired by Chen Dayu's unfulfilled ambition, directors and dramatists took over his unfinished work and continued to make efforts to create a free and open theatrical environment in Taiwan.

Nevertheless, it was definite that the experimental troupe had rehearsed Clouds of Doubt in Taiwan, even if there was no public performance. In the age of the white terror, some plays which targeted social ills could only be performed in the underground so as to avoid the authoritative censorship. There was practically no difference between rehearsal and public performance. Although there is no strong evidence, it is self-evident that Clouds of Doubt has exerted a significant influence on the Shakespeare circle in Taiwan. This play has also become a connecting point in the reception history of Shakespeare's plays on both sides of the Taiwan Strait.

\section{Performances of Shakespeare's Plays in Taiwan during Kuomintang Martial Law Period}

It was after 1949 that Shakespeare's plays began to be rooted in Taiwan, with the enthusiasm and efforts of the translators, scholars and theatrical directors, who moved to Taiwan from the mainland. On May $19^{\text {th }} 1949$, the Kuomintang officially declared Taiwan to be under the martial law. In the aspect of drama performance, it adhered to the principle of "drama serves the ruling power" (Shi 67) and made it subject to close scrutiny. During the period of martial law, Wang Shengshan, who laid foundation for directing drama in National Academy of Drama ${ }^{9}$ in Jiang'an, a small town in Sichuan Province, taught in the drama

9 National Academy of Drama was founded in Nanjing in 1935. During the AntiJapanese war, it was moved to Chongqing first, and then Jiang'an, the so-called cradle of Chinese Modern Drama. 
department of Chinese Culture University after moving to Taiwan and staged at least ten Shakespeare plays as public graduating performance. ${ }^{10}$

If Clouds of Doubt was excluded, then the first Chinese Shakespeare play in Taiwan would be The Story of the Prince's Revenge staged in 1962. This adaptation of Shakespeare's Hamlet was performed in Political Warfare College ${ }^{11}$ of Taiwan. In the early 1960 s, being a weapon of political struggle, theatres were completely controlled by the Kuomintang authorities after the martial law. The complete prohibition of mainland operas in Taiwan has become the main reason for Shakespeare's plays to appear on the military stage. In 1964, on the anniversary of the 400th birthday of William Shakespeare, the Political Warfare College was invited by the people in theatre circle to stage The Story of the Prince's Revenge for a whole week. Lee Man-gui, a director and the dean of the Department of Drama, positioned the play as the first formal performance of Shakespeare's plays in the post-war Taiwan theatre (Li 134).

After A Midsummer Night's Dream was staged by the Culture College in 1966, as the next Shakespeare play staged by the Culture College, King Lear was shown in the "National Gallery" of Taipei in 1967. Being staged again in 1968, the play should be the first Shakespeare play directed by Wang Shengshan. ${ }^{12}$ Wang resorted to visual elements in the play by using coloured lights to create different atmosphere on stage and giving Chinese names to characters to make the performance acceptable to the audience in Taiwan. With the success of King Lear directed by Wang Shengshan in 1986, the Confucian concept of filial piety and loyalty was inherited in Taiwan. During the period of martial law, Shakespeare's plays performed on the stage were full of entertaining effects and educational significance, which catered to the ideology of the ruling class at that time.

In 1970, the Culture College held the annual Hua Gang Art Exhibition, in which the performance of the drama department was called Hua Gang Drama Exhibition. ${ }^{13}$ From 1971 to 1979 , Hua Gang Drama Exhibition produced nine

${ }^{10}$ As for the detailed number and time of all the Shakespeare plays directed by Wang Shengshan, there are six versions with the interviews and investigation respectively done by Perng Ching-hsi, Jiang Longzhao, Chen Shu-fen, Li Kang-nian, Wang Shuhua and Wang Wan-rong. The information on the time of his earliest Shakespeare play and the number of the Shakespeare plays he staged in all his life are not consistent and still need further research.

${ }^{11}$ Founded in 1951, Fu Hsing Kang College was a military college located in Taipei. In 2006, it was transferred to the National Defense University of Taiwan and named the Political Warfare College.

${ }^{12}$ In the book Wang Shengshan written by Li Kang-nian, there is a contradictory record that King Lear was staged respectively in 1967 and 1968 (100; 178).

${ }^{13}$ Chinese Culture College was also known as Hua Gang, and in 1980 it was changed into Chinese Culture University. As it was built on Yang Ming mountain, Chang Chi- 
Shakespeare plays, eight of which were directed by Wang Shengshan, as the director of the drama department of the Culture College. Wang Shengshan required all students to participate in every detail of the theatre, such as stage design, performance, lighting, music, sound effect and costume design.

The political policies of the Kuomintang put emphasis on the interpretation of the Shakespeare's plays with the promotion of Confucianism, the revival of the inherent Chinese culture and the cultivation of loyalty and patriotism of the people. The central idea of Confucianism, self-cultivation, family planning, country governance and maintaining world peace also became the themes reflected in Shakespeare's plays in Taiwan during this period. Thus, it can be concluded that it was Chen Dayu, Liang Shih-chiu, Yu Er-chang, Wang Shengshan and other translators, scholars and theatrical directors who actually made Shakespeare's plays take root in Taiwan after the Kuomintang moved to Taiwan in 1949. It is under their joint efforts that the studies and performances of Shakespeare's plays in Taiwan gradually flourished and became popular among the public.

\section{Exchanges of Shakespeare Studies across the Taiwan Strait and the Developmental Prospect}

After the Reform and Opening-up, the Shakespeare Association of China was established in 1984, and two Chinese Shakespeare festivals were held respectively in 1986 and 1994. Shakespeare studies and performances in mainland China are greatly enhanced with the ever-lasting passion and painstaking efforts of several generations of the Chinese Shakespeareans. Leading members of the Association, such as Cao Yu, Yang Zhouhan, Li Funing, Fang Ping, Zhang Junchuan, Meng Xianqiang and many others, paved the way for the development of Shakespeare studies in China. Chinese scholars began to participate actively in international Shakespeare events in the 1990s.

In 1995, Sun Fuliang, one of the vice-presidents of the Shakespeare Association of China, visited Taiwan and was warmly welcomed by Chu Limin, $\mathrm{Hu}$ Yaoheng, Yang Maiyun, and many other Shakespeareans. Sun Fuliang gave a series of lectures on Shakespeare studies in mainland China at universities in Taiwan and proposed the establishment of Taiwan Shakespeare Association. This visit was reported on United Daily News of Taiwan with the title "The Whirlwind of Shakespeare from the Other Shore to Taiwan" on $22^{\text {nd }}$ February,

yun, the founder of the College, took the meaning of "In the beautiful China, phoenix is singing on high hills." And "Hua Gang" (Chinese hills) was chosen as the name for the site of the university. 
1995. It greatly enhanced the exchanges and communications across the Taiwan Strait. ${ }^{14}$

In 1996, the Association organized a delegation of Chinese Shakespeareans for the first time, including Fang Ping, Meng Xianqiang, Cao Shujun, Sun Fuliang, Gu Zhengkun, Zhang Chong and Yang Lingui, to attend the $6^{\text {th }}$ World Shakespeare Congress in Los Angeles. In 1997 Fang Ping was elected to be a member on the executive committee of the International Shakespeare Association (1997-2001). Currently on the Committee is Yang Lingui, who was first elected in the $9^{\text {th }}$ World Shakespeare Congress in Prague in 2011 and has been serving his second term since 2016 when the $10^{\text {th }}$ Congress was held in Stratford-upon-Avon and London.

When Shakespeareans in mainland China became active participants in exchanges with international circles of Shakespeare studies and more and more engaged themselves in Shakespearean events outside China in the early 1990s, they began to reach out to colleagues across the Taiwan Strait. After the 1992 consensus between the mainland China and Taiwan, cross-strait relations began to develop positively. Shakespeare scholars on both sides became willing to establish contact and participate in events organized on either side. For instance, some from Taiwan were invited and a few attended Shanghai Shakespeare festival held by the Shakespeare Association of China in 1994. A couple of papers from scholars in Taiwan were included in a collection of essays Chinese Shakespeare Yearbook, which was published in 1995 and edited by Meng Xianqiang. One festival attendant, Jiang Longzhao addressed the festival directly in his "Shanghai Shakespeare Festival, Eye-opener to a Veteran." Another piece in the collection contributed from across the Strait was Huang Meixu's "Comic Skills in Romeo and Juliet." The collection was a milestone of cooperation on Shakespeare studies on both sides of the Taiwan Strait. The editor, Meng Xianqiang once invited Huang Meixu and other Shakespeare scholars in Taiwan to participate in Shakespeare seminars held in mainland China and kept correspondences with Huang Meixu and others, including Chu Li-min, Yen Yuanshu, Perng Ching-Hsi and Ding Hongzhe. In a March 1995 letter to Meng,

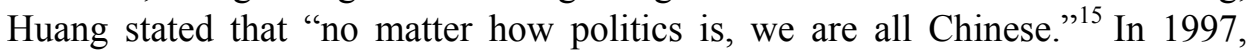
Huang Meixu lectured in Nanjing University, Soochow University and Shanghai Theatre Academy, greatly promoting the exchanges on Shakespeare studies on both sides of the Taiwan Strait. In recent years, more and more scholars have attended activities in mainland; for example, Wang Shuhua from Taiwan Normal

${ }^{14}$ See Meng, Xianqiang, “A Great Gathering of Shakespeare Studies: International Symposium on Shakespeare in China" (6-9).

15 The original letter was written in Chinese, collected in Letters on Chinese Shakespeare Studies, ed. Yang Lingui (Beijing: The Commercial Press, forthcoming). The sentence is translated by the author. 
University, presenting at the 2011 Shanghai International Shakespeare Forum organized by Yang Lingui at Donghua University. In 2016, Wang I-chun from the College of Humanities of Kaohsiung Medical University attended the seminar on "Shakespeare and the (Re)Creation of Early Modern Geographies" organized and chaired by Hao Tianhu and Garrett Sullivan at the World Shakespeare Congress held in Britain.

Over the years, under the leadership of many Shakespeare experts such as Chu Li-min, Yen Yuanshu, Perng Ching-Hsi, Chiu Chin-jung, Beatrice Lei and $\mathrm{Su}$ Tsu-chung, Taiwan Shakespeare studies have become more and more prosperous and the exchanges with the circle of Chinese Shakespeare studies have gradually increased. Chu Limin, Yen Yuanshu and Perng Ching-hsi are the three Shakespeare experts who have returned to Taiwan after receiving doctoral education in the United States and have played decisive roles in the continuous promotion of Shakespeare studies in Taiwan in different periods. All of them value the communications and exchanges on Shakespeare studies with the academic field of mainland China very much.

When Chu Limin and Yen Yuanshu were in charge of the department of Foreign Language and Literature of Taiwan University, they were determined to carry out reforms, which had a profound impact on the development of British and American literature, comparative literature education and Shakespeare studies in Taiwan. In 1972, they established Chung Wai Literary Monthly, a journal on studies of Chinese and foreign literature, which is now still among the top journals of TSSCI index of Taiwan. Through the platform of the journal, scholars from the mainland participate in the exchange of Shakespeare studies with colleagues across the strait. For example, Zhang Chong of Fudan University was once invited to preside over the special issue of Shakespeare in the $4^{\text {th }}$ issue of Chung Wai Literary Monthly in 2005, and published a paper "Timely Shakespeare," which exerted a great influence in Taiwan.

Of the invited speakers from Taiwan at Shakespeare events in the mainland, Perng Ching-Hsi is the most honoured and influential. As the leading Shakespeare expert in Taiwan now, he edited The Discovery of Shakespeare: Selected Works on Shakespeare Studies in Taiwan in 2000 and recalled the development of Shakespeare studies in Taiwan since Liang Shih-chiu edited William Shakespeare: A Miscellany in Celebration of the $400^{\text {th }}$ Anniversary of the Poet's Birth in 1966. He established NTU Shakespeare Forum in 2004. In the same year, his collected papers on Shakespeare studies, Close Reading of Shakespeare, was published. Up to now, he has translated 8 Shakespeare's plays and adapted 5 plays with Chen Fang, the proposer of the concept of Shake-xiqu. They adapted Yu opera Bond from The Merchant of Venice in 2009, Measure, Measure! from Measure for Measure in 2012, Questioning Heaven from King Lear in 2015 and adapted Peking opera and Hakka opera Betrayal from Cardenio in 2013 and 2014. Their adaptations of Shake-xiqu have been staged 
in America, Britain and mainland China and made a sensation. They have also adapted Hakka opera Waiting from As You Like It, which was staged in October 2019.

It is worth noting that theatrical experts can adapt Shakespeare's plays into the lines of Shake-xiqu, but it is left to Geng Yuqing, the national first-class composer of $\mathrm{Yu}$ opera of Henan Province and his disciples to do the work of composing the music and arranging the traditional musical instruments of $\mathrm{Yu}$ opera. Geng Yuqing has formed a unique artistic musical style in the aspect of self-emotional expression, refinement, objectification and individuation in his operatic vocal creation. It can be seen that without the score of mainland composers, it will be very difficult to form high standard works for the adaptation and creation of Shake-xiqu. This further proves that only when Shakespeare researchers on both sides of the Taiwan Strait work together and draw on their strengths, can they produce truly distinctive Shakespeare operas with Chinese characteristics.

Beatrice Bi-qi Lei, whose ancestral home was at Zhangzhou, Fujian Province, established Taiwan Shakespeare Database. The establishment of this database can permanently preserve the data of stills, videos, and reviews of Shakespeare's plays adapted and staged in Taiwan, leaving a long-term available resource for teaching and research, greatly promoting the external exchanges and studies of adapted Shakespeare's plays and the future development of local cross-cultural theatrical research. Beatrice Bi-qi Lei had once been invited to present a paper on Bond (an adaptation of The Merchant of Venice by Perng Ching-hsi and Chen Fang) at the International Shakespeare Academic Forum and the Commemoration of $100^{\text {th }}$ Anniversary of Zhu Shenghao's Birth held in Shanghai on October $28^{\text {th }}$ 2012. As an associate professor in Taiwan University, she was inspired by the depth and scope of Chinese Shakespeare studies and decided to establish Taiwan Shakespeare Association in December 2012. With the founding of TSA, she also established Asian Shakespeare Association with the help of Shakespeare experts in mainland China in 2014. Now she is also a member of the executive committee of the International Shakespeare Association.

The Chinese Shakespeare English Education Society was founded in Taiwan in 2017. Under the leadership of Chu Ching-mei, a professor in the department of drama at Taiwan University, the society is dedicated to the in-depth education of Shakespeare on campus. The society has brought Shakespeare's plays to all levels of schools in Taiwan so that many students in primary and secondary schools can also have access to Shakespeare's plays, watch Shakespeare's plays performed by the students of Taiwan University, and participate in Shakespeare workshops. It is hoped that Shakespeare's plays can connect the essences of eastern and western cultures by promoting them to the next generation in basic education. The scholars of Shakespeare studies on both 
sides of the Taiwan Strait hope to share Shakespeare's classic works with all Chinese-speaking people all over the world and let them appreciate the essence of world literature.

Along with the Shakespeare experts, directors of Shakespeare's plays in professional theatres are the main force of popularizing Shakespeare. In the field of performance of Shakespeare's plays, Contemporary Legend Theatre established by $\mathrm{Wu}$ Shing-kuo staged The Kingdom of Desire adapted from Macbeth in 1986, which marked the beginning of Shake-xiqu adaptation in Taiwan. Lee Kuo-Hsiu, Liang Zhimin, Lu Poshen, and many other leading theatrical directors in Taiwan, tried to adapt Shakespeare's plays into modern drama, musical drama, drama of glove puppetry and many other forms and staged their adaptations of Shakespeare's plays in mainland China and gained warm welcome and great success.

The performance of Shake-xiqu adapted in Taiwan also integrates elements of Chinese traditional opera in the process of innovation and breakthrough, contributing to the spread and development of Chinese opera on the world stage. Chen Fang, an expert on traditional Chinese opera and Shakespeare's plays in Taiwan, gave a clear definition of "Shake-xiqu" in her book Shake-xiqu: Cross-cultural Adaptation and Interpretation. It refers to "the Chinese traditional opera adapted from Shakespeare's plays, which is performed by real players" and "it is a case that cannot be ignored in the cross-cultural theatrical research of Asian Shakespeare's plays" (Chen Fang 16).

In 2004, Murray Levith, an American scholar, published Shakespeare in China. In the fifth chapter of the book, he made a detailed account of the reception of Shakespeare in Hong Kong and Taiwan, expanding the scope of the study of Shakespeare in China for the first time. However, in Murray Levith' account, he used the plural form when he mentioned China in the text for many times. For example, in the preface, he wrote: "Shakespeare in Chinas, as we shall see, is very much intertwined with Chinese politics, traditions, and societies" (Levith ix). His expression reflected the attitude of many in the west towards China at that time. The concept of "one China" was not recognized in the works of the Shakespeare researchers. It is obvious that Shakespeare in the globe, as we shall see, is very much intertwined with international politics, traditions, and societies. This phenomenon of not respecting the sovereignty of other countries should not appear in academic works. As we can see, this kind of odd expressions has gradually disappeared from academic works in recent years.

Therefore, to take a new look at Shakespeare in mainland China and Taiwan from a developmental perspective is very necessary and important. On $4^{\text {th }}$ May 2019, the International Shakespeare Conference was held by the Taiwan Shakespeare Association in Taiwan Normal University, where Liang Shih-chiu had once worked until his retirement. Shakespeare scholars from mainland China and Taiwan gathered together to share their studies on Shakespeare's 
plays eagerly. More communications and co-operations are believed to be carried out in the near future.

With the deepening of the internationalization of Taiwan Shakespeare studies, it is time to break down the cultural and academic barriers on both sides of the Taiwan strait and bring Taiwan Shakespeare studies back to the academic horizon of scholars in mainland China. Knowing the new trends of Shakespeare studies and adaptations on both sides can enhance the dialogues between the fields of Shakespeare studies in mainland China and Taiwan, strengthen the exchanges and cooperation, and contribute to jointly promoting the development of global Shakespeare studies and spreading traditional Chinese operas with the cultural appropriation of Shakespeare's plays.

\section{WORKS CITED}

Chen, Fang. Shake-xiqu: Cross-cultural Adaptation and Interpretation. Taipei: Taiwan Normal University Press, 2012.

Chen, Yilin. "A Study of Shakespeare's Plays during the Japanese Colonization of Taiwan and Its Role in English Education (1895-1945)." Project Report of the National Science Committee of the Executive Council of Taiwan, 20102011.

Chiu, Kun-liang. A Study on Taiwan Theatre during the Period of Japanese Occupation (1895-1945). Taipei: Culture Publishing Department of Independent Evening Newspaper, 1994.

—. Drifting for Thousands of Miles: Chen Dayu. Taipei: Cultural Construction Committee of the Executive Council, 2006.

Chiu, Mao-jing, and Beatrice Bi-qi Lei. "Shakespeare in Taiwan." Electronic Bulletin of Taiwan Research Center, College of Humanities, Taiwan University. http://ts.ntu.edu.tw/e_paper/e_paper_c.php?SID=63.27 $27^{\text {th }}$ April 2019.

Hiroshi, Seto. Shakespeare in China: A Reception History of Chinese Shakespeare. Trans. Chen Linghong. Guangzhou: Guangdong People's Press, 2017.

Huang, C. Y. Alex (now Alexa Alice Joubin). Chinese Shakespeares: Two Centuries of Cultural Exchanges. New York: Columbia University Press, 2009.

Huang, Yingzhe. "De-japanization" and "Re-sinicization": Post-war Cultural Reconstruction 1945-1947. Taipei: Wheat Field Press, 2017.

Hung, Shih-chian. "Immanent Exception: The Political Subject as a Generic Procedure." Chung Wai Literary Quarterly 47.3 (2018): 57-88.

Jiao, Tong. The Early Postwar Theatre in Taiwan. Taipei: Tai Yuan Press, 1990.

Lei, Beatrice Bi-qi. “'I May Be Straight, Though They Themselves Be Bevel': Taiwan's Early Shakespeare." Shakespeare's Asian Journey: Critical Encounters, Cultural Geographies, and the Politics of Travel. New York: Routledge, 2017. 89-108.

Levith, Murray. Shakespeare in China. London: Continuum, 2004. 
Li, Huang-liang. Lee Man-gui. Taipei: Arts University of Taipei, 2003.

Li, Kang-nian. Wang Shengshan. Taipei: Cultural Construction Committee of the Executive Council, 2006.

Liang, Shih-chiu, ed. William Shakespeare: A Miscellany in Celebration of the $400^{\text {th }}$ Anniversary of the Poet's Birth. Taipei: The Institute of Compilation and Translation, 1966.

Liu, Joyce C. H. "Why Badiou in Taiwan?" Chung Wai Literary Quarterly 47.3 (2018): 13-19.

Lv, Su-shang. The History of Film and Theatre in Taiwan. Taipei: Hua Yin Press, 1961.

Meng, Xianqiang. A Brief History of Chinese Shakespeare Studies. Changchun: Northeast Normal University Press, 2016.

"A Great Gathering of Shakespeare Studies: International Symposium on Shakespeare in China." Sichuan Drama 2 (1999): 6-9.

Chinese Shakespeare Yearbook. Changchun: Northeast Normal University Press, 1995.

Quiller-Couch, A. T. Historical Tales from Shakespeare. London: Edward Arnold, 1899.

Shi, Wan-shun. "The Production of the Empire: Kawakami Otojiro's Othello and Taiwan." Art Review 1 (2008): 78-92.

Teruo, Tarumoto, trans. Li Yanli. The Book on the Unjust Case of Lin Shu. Shanghai: Commercial Press, 2018.

Trivedi, Poonam. Re-playing Shakespeare in Asia. New York: Routledge, 2010.

Wu, Peichen. "Japanese Adaptation of Othello and the Colony Taiwan: Focusing on the Performance Records and Theatrical Reviews on Taiwan Daily News." The Colony and the City. Ed. Chen Fang-ming. Taipei: Chengchi University Press, 2014. 39-52.

"The Peripheral Body of Empire: Shakespearean Adaptations and Taiwan's Geopolitics." Re-playing Shakespeare in Asia. Ed. Poonam Trivedi and Minami Ryuta. London: Palgrave Press, 2000. 235-250.

$\mathrm{Xu}$, Junya. "Research on Lin Shu and His works in Taiwan." Chung Cheng Chinese Studies 1 (2012): 251-280.

_. "The Early Propagation of Shakespeare's Play and Its Acceptance in Taiwan." Journal of Sichuan International Studies University 1 (2013): 42-46.

Yamamoto, Sumiko. The Introduction of the Western Theatre to Japan. Tokyo: Bunka Shobō Hakubunsha, 1992.

Yukari Yoshihara, "Raw-Savage's Othello: The First-staged Japanese Adaptation of Othello (1903) and Japanese Colonialism." Shakespeare and the Ethics of Appropriation, 2014.

Zhu, Jungong. "On the Merits and Demerits of Zhu Shenghao's Translation of Shakespeare's Plays." China Translation 5 (1998): 24-26. 